Journal of Korean Powder Metallurgy Institute

Vol. 18, No. 5, 2011

DOI: http://dx.doi.org/10.4150/KPMI.2011.18.5.430

\title{
Morphologies of Brazed NiO-YSZ/316 Stainless Steel Using B-Ni2 Brazing Filler Alloy in a Solid Oxide Fuel Cell System
}

\author{
Sungkyu Lee*, Kyoung-Hoon Kang, Hyun Seon Hong*, and Sang-Kook Woo ${ }^{a}$ \\ Plant Engineering Center, Institute for Advanced Engineering, 633-2 Goan-ri, \\ Baegam-myeon, Cheoin-gu, Yongin-si, Gyeonggi-do 449-863, Korea \\ ${ }^{a}$ Energy Materials Research Center, Korea Institute of Energy Research 71-2 Jang-dong, \\ Yuseong-gu, Daejeon 305-343, Korea \\ (Received June 28, 2011; Revised July 27, 2011; Accepted August 20, 2011)
}

\begin{abstract}
Joining of NiO-YSZ to 316 stainless steel was carried out with B-Ni2 brazing alloy ( $3 \mathrm{wt} \% \mathrm{Fe}, 4.5$ $w t \% \mathrm{Si}, 3.2 \mathrm{wt} \% \mathrm{~B}, 7 \mathrm{wt} \% \mathrm{Cr}$, Ni-balance, m.p. $\left.971-999^{\circ} \mathrm{C}\right)$ to seal the NiO-YSZ anode/316 stainless steel interconnect structure in a SOFC. In the present research, interfacial (chemical) reactions during brazing at the NiO-YSZ/ 316 stainless steel interconnect were enhanced by the two processing methods, a) addition of an electroless nickel plate to NiO-YSZ as a coating or b) deposition of titanium layer onto NiO-YSZ by magnetron plasma sputtering method, with process variables and procedures optimized during the pre-processing. Brazing was performed in a cold-wall vacuum furnace at $1080^{\circ} \mathrm{C}$. Post-brazing interfacial morphologies between NiO-YSZ and 316 stainless steel were examined by SEM and EDS methods. The results indicate that B-Ni2 brazing filler alloy was fused fully during brazing and continuous interfacial layer formation depended on the method of pre-coating NiO-YSZ. The inter-diffusion of elements was promoted by titanium-deposition: the diffusion reaction thickness of the interfacial area was reduced to less than $5 \mu \mathrm{m}$ compared to $100 \mu \mathrm{m}$ for electroless nickel-deposited NiO-YSZ cermet.
\end{abstract}

Keywords: Active brazing, Interfacial morphology, NiO/YSZ cermet, B-Ni2 brazing filler alloy, Magnetron plasma sputtering deposition

\section{Introduction}

Recently, fuel cells are becoming a primary energy generation method for their high power generation efficiency and regarded as a environment-friendly measures to counter soaring petroleum price and world wide concerns on greenhouse gases. The solid oxide fuel cell (SOFC) does not require a liquid electrolyte and can be operated continuously and reliably at high temperature. SOFC consists of an anode, interconnect material, cathode, and a solid electrolyte. The most commonly used anode and cathode materials are NiO-YSZ (yttria-stabilized zirconia) and LSM (LaSrMn, strontium-doped lanthanum manganate), respectively [1-3].
Cr- or Fe-based alloys have better oxidation and corrosion resistance than the conventional La-Ga-Cr and La-Sr-Cr oxides and their compatibility of thermal expansion coefficients with those of other SOFC components is also satisfactory. Therefore, they are widely being considered as promising interconnect materials and they could significantly reduce SOFC operating temperature and improve SOFC reliability. However, reliable sealing of the NiO-YSZ anode/ interconnect structure in a SOFC still remains a significant engineering barrier to continuous running of SOFC for more than $2000 \mathrm{~h}$ [3].

In general, molten metals and alloys do not wet ceramic or cermet substrates due to the highly different nature of their inter-atomic bonds, and this is

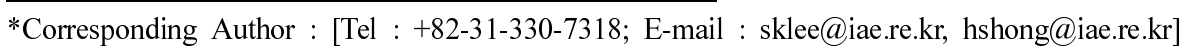


especially true of highly stable $\mathrm{MgO}, \mathrm{ZrO}_{2}$, and $\mathrm{Al}_{2} \mathrm{O}_{3}$. Much higher interfacial energy than that of the un-joined surfaces caused this to happen. However, a chemical reaction between the metal and the ceramic substrate could lower the overall surface energy of the metal/ceramic interface and increase its stability. In many ceramic/metal joining applications, interfacial (chemical) reactions are promoted by modifying the interface areas by the addition of active elements, such as titanium, hafnium, and zirconium. These active elements ensure the formation of chemically stable ceramic/metal interface $[3,4]$.

For proper brazing of metal/ceramic interface, special attention must be paid to three different aspects [4]:

a) The melting range of the brazing alloy must be lower than that of the parent substrates.

b) The solidus point of the brazing alloy must lie above the operating temperature of the brazed joint.

c) The brazed joint must be able to withstand the SOFC operating conditions, such as temperature and other gaseous environments.

In the previous research [5], interfacial (chemical) reactions during brazing at the NiO-YSZ/316 stainless steel interconnect were modified by addition of an electroless nickel plate layer to NiO-YSZ composite, followed by application of moderate loading at a normal to the joint surface using an optimally designed weighting jig on NiO-YSZ composite during brazing. However, it was necessary to examine the effect of the following pre-conditioning methods on the interfacial morphologies while preventing further oxide formation and improving wettability:

a) Addition of an electroless nickel plate layer to NiO-YSZ cermet as a coating

b) Deposition of titanium layer onto NiO-YSZ cermet by magnetron plasma sputtering method using an optimally designed jig.

The NiO-YSZ composite pre-conditioned by either a) or b) was brazed to 316 stainless steel interconnect material by using a commercially available B$\mathrm{Ni} 2$ brazing alloy and the brazed joints were subsequently sectioned and examined by scanning electron microscopy (SEM) and energy dispersive spectroscopy (EDS) to explain the interfacial reactions occurring at the NiO-YSZ/316 stainless steel interfaces.

\section{Experiment}

\subsection{Preparation}

A commercially available $\mathrm{B}-\mathrm{Ni} 2$ brazing filler alloy (3 wt \% Fe, 4.5 wt $\% \mathrm{Si}, 3.2 \mathrm{wt} \% \mathrm{~B}, 7 \mathrm{wt} \% \mathrm{Cr}$, Ni-balance, m.p. $971-999^{\circ} \mathrm{C}$ ) from Metglas ${ }^{\circledR}$, Inc. in its foil $(100 \mu \mathrm{m})$ presentation was used. Both substrates and the B-Ni2 brazing alloy were ultrasonically cleaned in acetone for about 60 minutes. NiOYSZ rod was further pre-conditioned to promote braze adhesion by either a) addition of an electroless nickel plating as a coat or b) deposition of titanium layer onto $\mathrm{NiO}-\mathrm{YSZ}$ by magnetron plasma sputtering method using an optimally designed jig.

\subsubsection{Pre-coating of NiO-YSZ rod}

a) Electroless nickel coating

Ultrasonically cleaned NiO-YSZ rod was electroless nickel plated by the following unit steps:

i) Degreasing by maintaining in a stirred $20-30 \%$ $\mathrm{NaOH}$ solution heated to $60^{\circ} \mathrm{C}$.

ii) Etching in a $\mathrm{NaF}$ solution for $10 \mathrm{~min}$ at ambient temperature to break down thin surface oxides.

iii) Catalyzation by treating in $25 \% \mathrm{HCl}$ solution containing $\mathrm{Sn}$ and $\mathrm{Pd}$ compounds for 2-10 $\mathrm{min}$ at ambient to maximum $40^{\circ} \mathrm{C}$.

iv) Acceleration by immersing in $10 \% \mathrm{H}_{2} \mathrm{SO}_{4}$ solution for 30 to $60 \mathrm{sec}$ at ambient temperature.

v) Electroless nickel plating by dipping in $\mathrm{NiB}$ or NiP solution for $20 \mathrm{~min}$ at 60 or $90^{\circ} \mathrm{C}$, respectively.

The NiO-YSZ rod was thoroughly rinsed in running deionized water between unit steps described above, i) to v)

2.1.2. Deposition of titanium layer onto NiO-YSZ by magnetron plasma sputtering method

The NiO-YSZ rod was loaded in a specially designed jig as shown in Fig. 1 and the jig assembly 


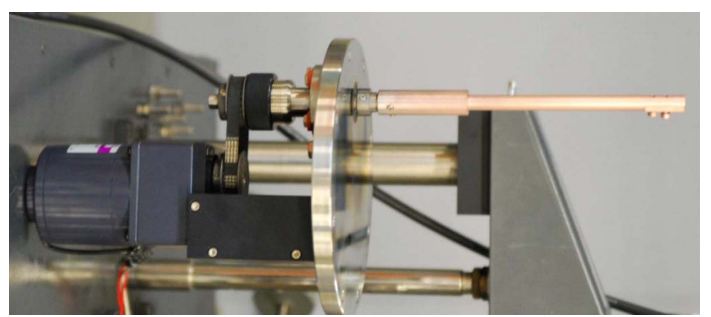

Fig. 1. A specially designed jig for deposition of titanium layer onto NiO-YSZ cermet rod by magnetron plasma sputtering.

was suitably located inside the top of a magnetron plasma sputter coating system used by Zhang et al. [6]. The sputtering target was a $10 \mathrm{~cm}$ dia. $\times 4 \mathrm{~mm}$ thickness titanium disk (99.9\% purity) and the NiOYSZ rod was uniformly sputter-deposited to $0.5 \mu \mathrm{m}$ for $35 \mathrm{~min}$ at the rate of $2.5 \AA / \mathrm{min}$ after the chamber was evacuated to base pressure of $5 \times 10^{-6}$ Torr. The 4 in dia. unbalanced magnetron sputter source generated titanium target power in bi-polar pulsed mode and target surface magnetization of $0.7 \mathrm{~A}$ and 500 gauss, respectively. The distance between unbalanced magnetron source and the NiO-YSZ rod was maintained at about $70-80 \mathrm{~mm}$ and the magnetic field was optimally generated by computer simulation. The NiO-YSZ jig assembly was heated to and maintained at $200^{\circ} \mathrm{C}$ by a combination of halogen lamp heaters and Ar plasmas. To improve titanium coating uniformity and to avoid excessive heat build up in the NiO-YSZ, the jig assembly was rotated at maximum $20 \mathrm{rpm}$.

\subsubsection{Final processing before brazing}

The pre-coated NiO-YSZ rod was further processed for actual brazing. Fig. 2 shows approximate cross-section of finally prepared assembly of NiOYSZ/316 stainless steel interconnect. B-Ni2 brazing filler alloy foil (100 $\mu \mathrm{m}$ thick) was cut into disk forms which were piled at the bottom of hollow 316 stainless steel fixture. $30 \mathrm{~mm} \times 10 \mathrm{~mm}$ B-Ni2 brazing filler alloy strip was also cut out and wrapped around the lower part of the pre-coated NiO-YSZ rod.

Controlled environment affords maximum wetting and braze flow inhibitors, "stop-off" materials, were

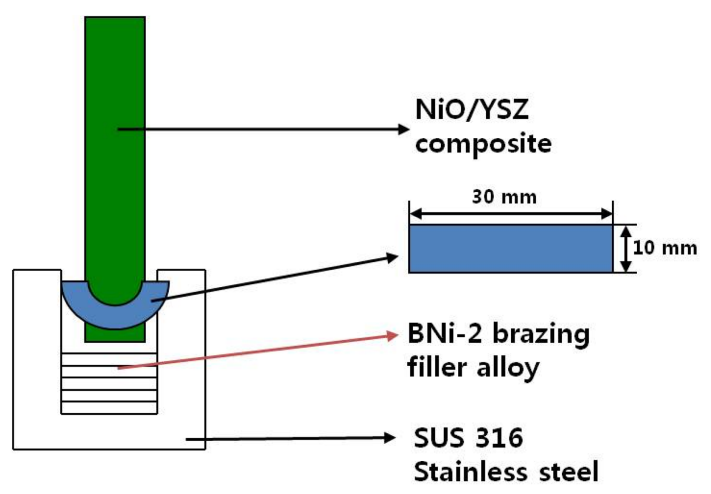

Fig. 2. Approximate cross-section of finally prepared assembly of NiO-YSZ/316 stainless steel interconnect for brazing.

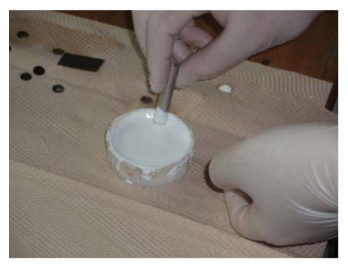

a)

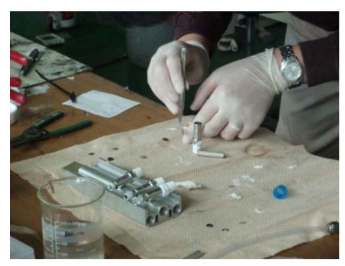

c)

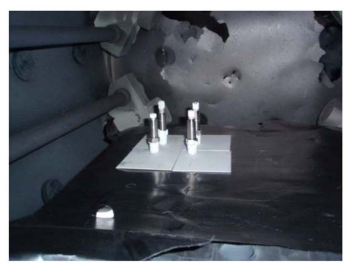

e)

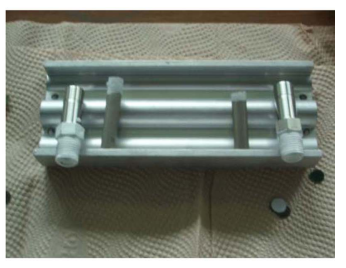

b)

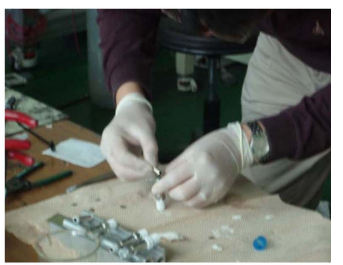

d)
Fig. 3. Detailed sequence of preparation for NiO-YSZ/BNi2/316 stainless steel interconnect assembly of Fig. 2: a) Application of stop-off at the tip of the NiO-YSZ cermet rod; b) Drying of stop-off on a drying jig; c) Loading BNi2 brazing filler alloy disks; d) Insertion of NiO-YSZ cermet rod; e) Loading into the chamber of a cold-wall vacuum furnace, ready for brazing.

applied to mask off areas of the assembly parts, such as holes and threads, where excess flow of the filler metal would be undesirable. In the present research, stop-off material was applied at the tip of NiO-YSZ 
rod and outside area of 316 stainless steel fixture. Sequence of preparation for NiO-YSZ/316 stainless steel interconnect is detailed in Fig. 3a-e: stop-off materials are applied at bright white spots.

\subsection{Furnace brazing and post examination}

NiO-YSZ/316 stainless steel interconnect assembly of Fig. 3e was installed in a typical cold-wall vacuum furnace to perform actual brazing with sequence of operations illustrated in Fig. 4. The brazed assembly was cold-mounted and sectioned using a diamond saw, both vertically and horizontally, as shown in Fig. 5, before examination of interfacial morphologies between NiO-YSZ and 316 stainless steel using scanning electron microscopy (SEM) and energy dispersive spectroscopy (EDS). EDS analyses of the brazed joint were carried out to detect elements of $\mathrm{Ni}, \mathrm{Fe}$, and $\mathrm{Zr}$ down the marker lines of Figs. $6 \mathrm{~b}$ and $7 \mathrm{~b}$ and to analyze the post-brazing reac-

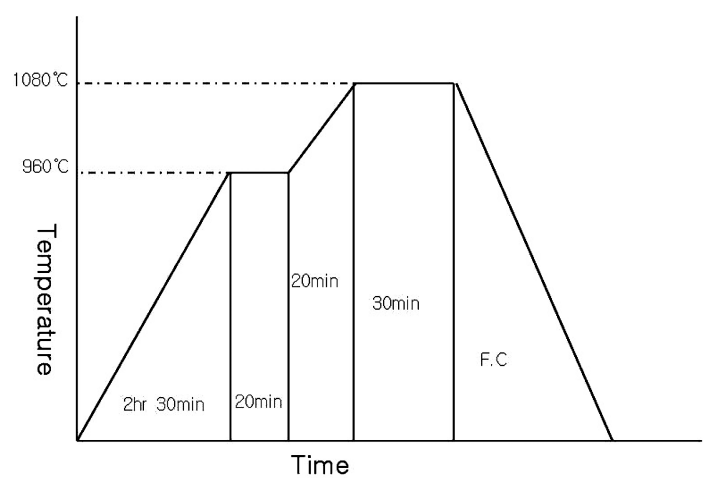

Fig. 4. Sequence of vacuum furnace operation for brazing. F.C. denotes furnace cooling.

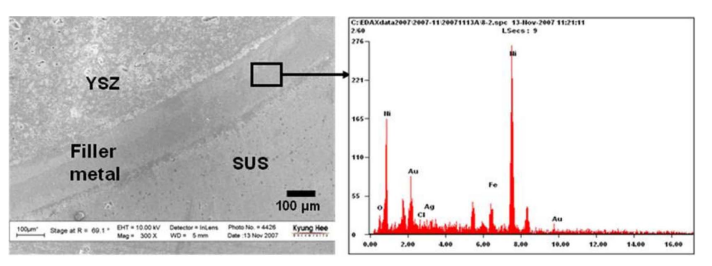

a)
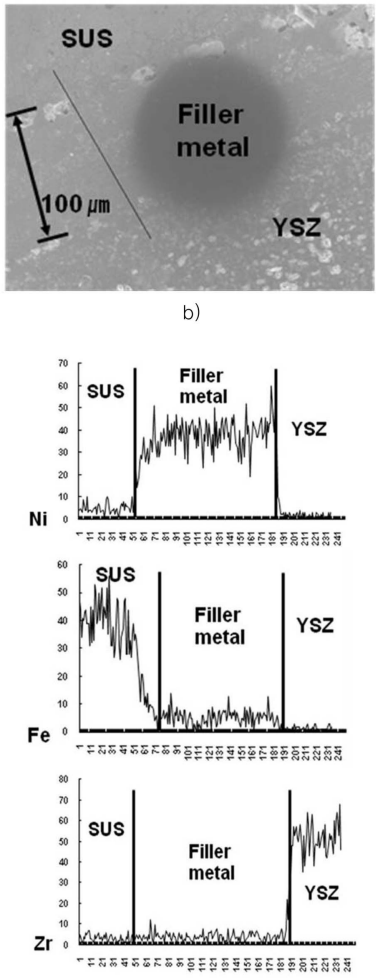

c)

Fig. 6. Post-brazing EDS analyses of electroless nickelplated NiO-YSZ/B-Ni2/316 stainless steel assembly: a) Micro-structural characteristics of the brazed interface and EDS elemental peaks; b) Micro-structural characteristics of the brazing filler alloy and c) marker line for EDS analyses of $\mathrm{Ni}$, $\mathrm{Fe}$, and $\mathrm{Zr}$.
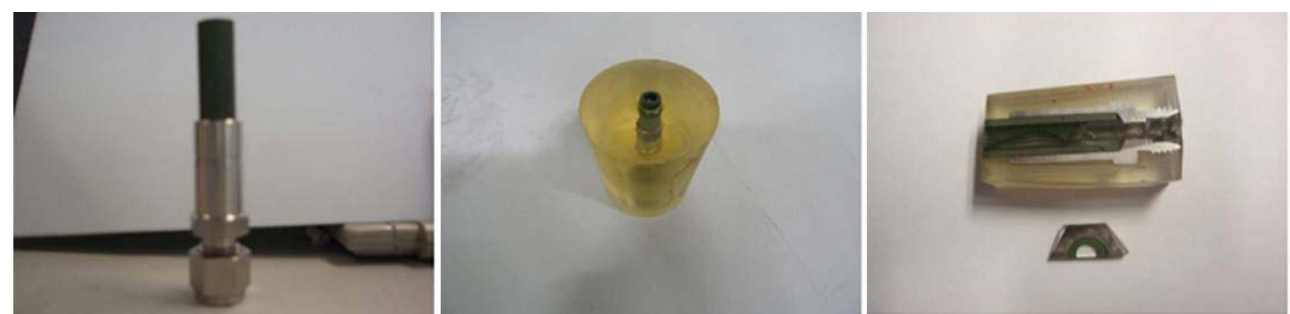

Fig. 5. Post-brazing sample preparation for SEM and EDS examination, showing brazed NiO-YSZ/316 stainless steel assembly, cold mounting of brazed assembly, and brazed assembly cut vertically and horizontally using a diamond saw, from left to right. 


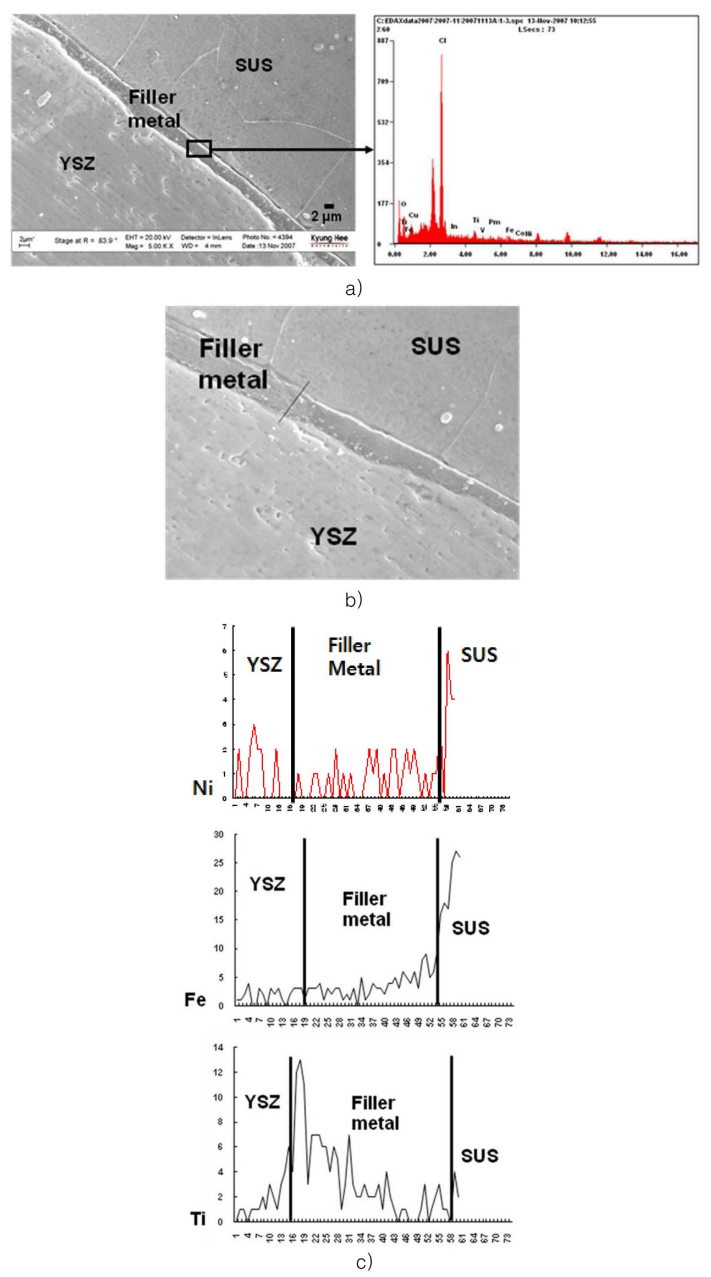

Fig. 7. Post-brazing EDS analyses of Ti-deposited NiOYSZ/B-Ni2/316 stainless steel assembly: a) Micro-structural characteristics of the brazed interface and EDS elemental peaks; b) Micro-structural characteristics of the brazing filler alloy and c) marker lines for EDS analyses of $\mathrm{Ni}, \mathrm{Fe}$, and $\mathrm{Ti}$.

tion phases in the NiO-YSZ/316 stainless steel joint, Figs. 6a and 7a.

\section{Results and Discussion}

Figs. $6 \mathrm{~b}$ and $7 \mathrm{~b}$ show the morphologies of the interface in the brazed NiO-YSZ/B-Ni2 alloy/316 stainless steel joint. Regardless of pre-processing method used, either electroless nickel plating or deposition of titanium via magnetron plasma sputtering, B-Ni2 brazing alloy was fused fully and diffusion occurred to produce a continuous interfacial layer between NiO-YSZ and 316 stainless steel. Three clearly identifiable regions have formed due to interactions between the B-Ni2 brazing filler alloy and the substrates. Although details on grain size in the interfacial layer of fused B-Ni2 filler metal region is not easily distinguishable from Figs. $6 \mathrm{~b}$ and $7 \mathrm{~b}$, it is strongly inferred that the interfacial layer consisted of finer grains than those of 316 stainless steel because B-Ni2 filler metal alloy completely fused during brazing and subsequently solidified rapidly during fast cooling [7-9]. EDS analysis of the joint is also carried out to investigate diffusion reaction of $\mathrm{Ni}, \mathrm{Fe}$, and $\mathrm{Zr}$ in the brazed joint as shown in Figs. 6c and 7c, where Ni, Fe, Zr and $\mathrm{Ti}$ peak intensity variations across the brazed bonds are identified.

\subsection{Interface reactions in electroless Ni-plated} NiO-YSZ/B-Ni2/316 stainless steel

The thickness of the interfacial layer is about 200 $\mu \mathrm{m}$ as measured by SEM/EDS, Figs. 6a. Fig. 6a has revealed that the brazed joint contains more of $\mathrm{Ni}$ and less of Fe. The EDS peak sizes for $\mathrm{Ni}$ and $\mathrm{Fe}$ are directly proportional to respective compositions of $\mathrm{Ni}$ and $\mathrm{Fe}$ in the B-Ni2 brazing filler alloy. Therefore, significant inter-diffusion of $\mathrm{Ni}$ and $\mathrm{Fe}$ did not take place to and from B-Ni2 brazing alloy, respectively. Besides, it is highly questionable that significant amount of electroless-plated nickel diffused from NiO-YSZ into 316 stainless steel up the concentration gradient as shown in Fig. 6c. This is further substantiated by missing $\mathrm{Zr}$ peak in Fig. 6a: very little zirconium, if any, has diffused into 316 stainless steel across the B-Ni2 brazing filler alloy and the zirconium EDS peaks of Fig. 6c in 316 stainless steel and B-Ni2 brazing filler alloy regions are too weak to positively substantiate any measurable diffusion of zirconium from NiO-YSZ cermet.

Interfacial strength of brazed joint, such as B-Ni2 in the present research, critically depends on interdiffusion of elements from brazing filler alloy to 
either side of it [5, 7-8] into NiO-YSZ and 316 stainless steel, which would relieve the stress concentration in the interface. Thus, the elemental distribution of Fig. $6 \mathrm{c}$ could be regarded as a qualitative indication of interfacial bonding integrity and thus electroless Ni-plated NiO-YSZ/B-Ni2/316 stainless steel joint would most probably result in insufficient interdiffusion of $\mathrm{Ni}, \mathrm{Fe}$, and $\mathrm{Zr}$ to and from B-Ni2 brazing filler alloy. This in turn could lead to possibility of poorly bonded brazed joints, one example is shown in Fig. 8a as a corroboration.

\subsection{Interface reactions in Ti-deposited NiO-YSZ/ B-Ni2/316 stainless steel}

Fig. 7a shows that brazed joint thickness has been reduced to less than $5 \mu \mathrm{m}$ which is quite contrary to Fig. 6a. From Fig. 6a, it is strongly suggested that the B-Ni2 brazing filler alloy extensively reacted with the titanium deposited onto the NiO-YSZ. From EDS analysis, it is possible to estimate that the B-Ni2/ $\mathrm{NiO}-\mathrm{YSZ}$ reaction led to the precipitation of several distinct phases from originally single phase materials. Also, solid solution of titanium and nickel presumably formed at the brazed joint [7-9]. It is also important to note that EDS analyses tend to overestimate the presence of light elements such as oxygen and chlorine in Fig. 7a and the EDS peak sizes of $\mathrm{Ni}, \mathrm{Fe}$, and $\mathrm{Ti}$ should be interpreted in terms of their respective compositions. It is quite noteworthy that titanium peak size is significantly larger than $\mathrm{Fe}$ and almost comparable to that of nickel, which clearly indicated the presence of solid solution in the brazed joint.

Unlike electroless nickel-plated NiO-YSZ discussed in section 3.1, extensive diffusion of titanium well into the 316 stainless steel across the brazing filler alloy interlayer is substantiated by Fig. 7e. It is also to be noted that extensive diffusion of nickel into NiO-YSZ cermet occurred across the brazing filler alloy. Therefore, deposition of titanium on the NiOYSZ promoted inter-diffusion of $\mathrm{Ni}$ as shown in Fig. 7c, which is quite contrary to Fig. 6c. Significant

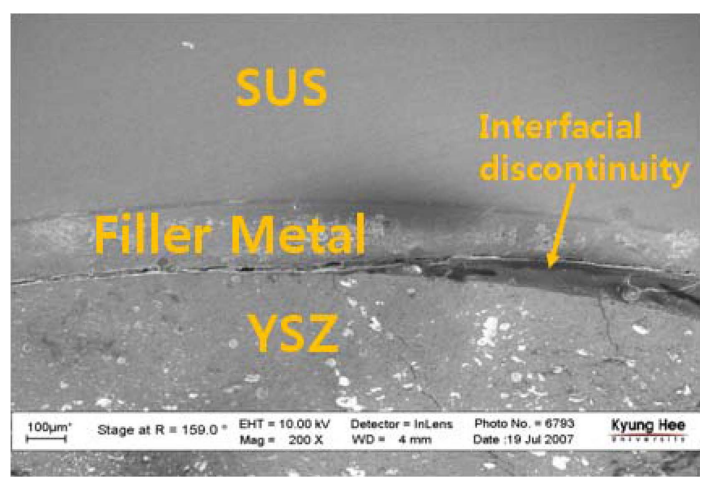

(a)

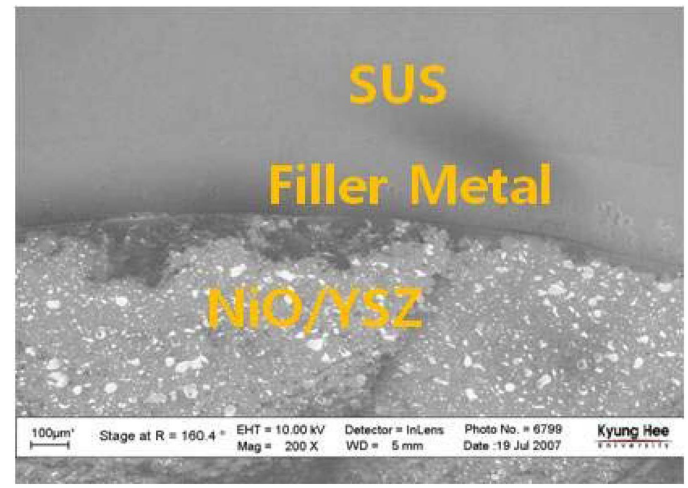

(b)

Fig. 8. Optical micrographs of brazed joints: (a) Poorly bonded interface in electroless Ni-plated NiO-YSZ/B-Ni2/ 316 stainless steel and (b) Interfacial integrity in Ti-deposited NiO-YSZ/B-Ni2/316 stainless steel.

improvement in interfacial integrity is strongly deduced from continuous interfacial layer between $\mathrm{NiO}-Y S Z$ and 316 stainless steel (Fig. 8b). In view of this, interfacial strength at the Ti-deposited NiOYSZ interface is greater than that of electroless Niplated interface. This is most probably explained by eutectic-free joint upon solidification [10]. Therefore, titanium deposition on the NiO-YSZ cermet adequately promoted inter-diffusion of $\mathrm{Ni}$ into $\mathrm{NiO}-$ YSZ as shown by Fig. 7c. Similar reasoning can be applied to inter-diffusion of iron, too. Fig. 7c shows existence of $\mathrm{Fe}$ concentration gradient within the brazing filler alloy interlayer but it is not observed in Fig. 6c. Again, magnetron plasma sputtering deposition of titanium onto the NiO-YSZ somehow promoted inter-diffusion of Fe, too [11, 12]. 


\section{Summary}

Continuous interfacial layer formation by complete fusion of B-Ni2 brazing filler alloy critically depended on the method of pre-coating NiO-YSZ: magnetron plasma sputtering deposition of titanium onto the NiO-YSZ promoted inter-diffusion of both nickel and iron across the B-Ni2 interlayer into NiOYSZ while titanium diffused into 316 stainless steel substrate. On the other hand, electroless nickel-coating on NiO-YSZ cermet did not show any noticeable inter-diffusion of nickel and iron across the B$\mathrm{Ni} 2$ interlayer. Therefore, titanium-deposited NiOYSZ showed quite strong bonding to the 316 stainless steel substrate by promoting inter-diffusion of nickel and iron. When the inter-diffusion of elements was promoted by titanium-deposition, the diffusion reaction thickness of the interfacial area was reduced to less than $5 \mu \mathrm{m}$ compared to $100 \mu \mathrm{m}$ for electroless nickel-deposited NiO-YSZ cermet.

\section{Acknowledgments}

Ministry of Knowledge Economy, Republic of Korea is gratefully acknowledged for support through the Hydrogen Energy R \& D Center (21st Century Frontier R \& D Programs). Mr. S.-D. Kim assisted in magnetron plasma sputtering deposition.

\section{References}

[1] B. C. H. Steele and A. Heinzel: Nature, 414 (2001) 345.

[2] G. J. K Acres: J. Power Sources, 100 (2001) 60.

[3] Y.-W. Yen, C.-Y. Lee, D.-P. Huang and J.-W. Su: J. Alloy Compd., 466 (2008) 383.

[4] R. Arróyave and T. W. Eagar: Acta Mater., 51 (2003) 4871.

[5] S. Lee, K.-H. Kang, H. S. Hong, Y. Yun, J.-H. Ahn and S. K. Woo: Can. Metall. Q., 50 (2011) 72.

[6] L. Zhang, L. Q. Shi, Z. J. He, B. Zhang, Y. F. Lu, A. Liu and B. Y. Wang: Surf. Coat. Technol., 203 (2009) 3356.

[7] P. Liu, Y. Li, J. Wang and J. Guo: Mater. Res. Bull., 38 (2003) 1493.

[8] C. Xia, Y. Li, U. A. Puchkov, S. A. Gerasimov and J. Wang: Vacuum, 82 (2008) 799.

[9] J. Wang, Y. Li and S. A. Gerasimov: Bull. Mater. Sci., 30 (2007) 415.

[10] X. Wu, R. S. Chandel, S. H. Pheow and H. Li: Mater. Sci. Eng. A, 288 (2000) 84.

[11] G. W. Liu, W. Li, G. J. Qiao, H. J. Wang, J. F. Yang and T. J. Lu: J. Alloy Compd., 470 (2009) 163.

[12] G. W. Liu, G. J. Qiao, H. J. Wang, J. F. Yang and T. J. Lu: J. Eur. Ceram. Soc., 28 (2008) 2701. 